\title{
Integration of Media Literacy Education and Employee Assistance Program (EAP)
}

\author{
Haoyu Wang \\ Beijing No.27 High School \\ Beijing, China 100006
}

\author{
Zifeng Han \\ Miyun Branch of Capital University of Economics and \\ Business \\ Beijing, China 101500
}

\begin{abstract}
With the development of economy, the role of media information in public life is more important. This paper makes a brief introduction to the connotation of media literacy education, the development of media literacy education, as well as the development of employee assistance programs and employee assistance programs. It also clarifies the role of media literacy education in EAP services among different clients. At the same time, this paper makes the analysis on the necessity and feasibility of the integration of media literacy education and employee assistance program. Finally, the author puts forward the thoughts and suggestions on the media literacy education developed in the employee assistance program.
\end{abstract}

Keywords-media literacy; employee assistance program; EAP; education; development

\section{INTRODUCTION}

Today media information has entered the era of big data, and people travel back and forth in media information every day. Therefore, media information has become an important factor in the quality life of people. And it also affects the formation of people's world outlook, outlook on life, and values.

\section{MEDIA LITERACY EDUCATION}

\section{A. Media}

Media is an intermediary that connects transmission and reception. It refers to the general name of the media, including traditional mass media such as television, movies, newspapers, radio and magazines, as well as new media such as the Internet and mobile phone communications. Marshall McLuhan proposed that "media was information", referring to changes in the scale, pace, or type of human beings caused by any progress in the form of media. That is to say, media forms bring "information" to human society in addition to the content of media. It is the nature of the medium through which people communicate, rather than the content of communication. That would have deep influences on the society.

\section{B. Literacy}

According to the "Modern Chinese Dictionary" edited by the dictionary editorial office of the Institute of Linguistics of the Chinese Academy of Social Sciences, the term "literacy" was interpreted as "the cultivation of daily life". According to the "Cambridge International Dictionary of English" edited by Proctor, "literacy" refers to "reading and writing, and cultural ability". In "Webster Advanced English Dictionary" edited by Merriam Webster Company, "literacy" is interpreted as "the quality and status of reading and writing".

\section{Media Literacy}

According to the definition of Media Literacy Research Center in the United States in 1992, media literacy refers to people's ability to choose, understand, question, evaluate, create and produce, as well as their ability to think and react when facing various kinds of media information. Media literacy means that people are active media users. People with media literacy are both content receivers and content creators. They can understand social and political content, effectively use code reproduction systems, and live in society with responsibility. Simply speaking, media literacy is the ability of people to interpret various forms of media information. [1]

\section{Media Literacy Education}

$\mathrm{Bu}$ Wei, the expert at the Institute of Journalism and Communication, Chinese Academy of Social Sciences believes that media literacy education includes four aspects. First is to understand basic media knowledge and how to use media. Second is to learn to judge the meaning and value of media messages. The third is to learn to create and disseminate information knowledge and skills. The fourth is to understand how to effectively use the mass media to develop themselves. The ideal state of media literacy education is that people's use of media will become a driving force for their development, and will not be used as a slave to the media and message of the mass media. [2]

\section{DEVELOPMENT OF MEDIA LitERACY EDUCATION}

\section{A. Development of Media Literacy Education in the UK}

The United Kingdom was the birthplace of media literacy education. In 1933, E.R. Lewis and Dennis Sampson published the cultural criticism book "Culture and the Environment: Cultivating Critical Sense". This article first 
proposed the concept of media literacy. At the same time, the United Kingdom was also the first country to incorporate media literacy education into the school curriculum system. In 1989, the British Department of Education incorporated media literacy education into the formal education system. By 1997, nearly two-thirds of schools in the United Kingdom had established media literacy courses. [3]

\section{B. Development of Media Literacy Education in the United States}

As the most diversified media industry in the world, the United States began its formal media literacy education at the end of the 1960s. It experienced roughly three stages: the prevention phase, facing-it phase, and the transition phase. The goals of the media literacy education in the United States include five aspects. The first is to prevent the harm brought by the media. The second is to promote students' physical and mental health. The third is to form students' civic awareness and democratic awareness. The fourth is to master learning and communication tools. And the fifth is to understand the media as an art form.

\section{Development of Media Literacy Education in Canada}

Canada is a country where media literacy education is widely used. Due to the efforts of the Media Literacy Education Association, Ontario was the first to introduce media literacy education into classroom education. By 1987, Canada had 50 colleges and universities providing more than 90 media literacy education programs, including a single short-term course and a full four-year degree program. By the early 1990s, media literacy education associations had been established in most provinces across Canada.

\section{Development of Media Literacy Education in Australia}

Australia is the country which attaches most importance to media literacy. It is also the first country in the world to make media literacy education be a required course for every student in the kindergarten to junior high school through the decree. Australian scholars believe that the media have a lot of information. And they need to explain the media image and the concept of media. For the healthy development of students, we must cultivate children's critical vision and speculative brain. And then, they would identify the true and false media. The children could correctly face media information and not be affected by media information.

\section{E. Development of Media Literacy Education in Japan}

Japan is one of the countries in Asia that started media literacy education earlier. One of the most prominent characteristics of media literacy in Japan is to focus on the ability to accept and use media information. In 2002, Japan announced white paper on media literacy education. At the same time, media education is practiced by formal and adult education systems.

\section{F. Development of Media Literacy Education in China}

Hong Kong, Macao, and Taiwan regions began to gradually develop media literacy education in the 1990 s. The mainland media literacy education started late. In June 1997, the "Media Communication and Youth Development Research Center" established by the Institute of Journalism and Communication of the Chinese Academy of Social Sciences became the first step in media literacy education in China. Until 2004, Shanghai Jiaotong University opened a media literacy education course and became the first university in the country to implement media literacy classroom education. So far, there is no large-scale curriculum for media literacy education, and there are few media literacy books written for on-the-job employees. [4]

\section{THE DEVElopMENT OF EMPLOYEE ASSISTANCE PROGRAM}

\section{A. Employee Assistance Program}

The Employee Assistance Program (EAP) is a systematic, long-term assistance and benefit plan set up by the organization for its members. Through the professional's diagnosis of the organization, recommendations and professional guidance, training and consultation of the members and their families, it can help solve the psychological and behavioral problems of the members and their families. And then, it would maintain the psychological health of the members and improve the performance and organizational management.

\section{B. Development of Employee Assistance Program}

In the early stage, EAP was mainly focused on helping employees solve problems related to alcohol abuse or drug abuse. After decades of development, it has gone far beyond the original model. The main contents of EAP now include work stress, mental health, disaster events, and career problems, healthy lifestyles, legal disputes, financial issues, weight loss, and eating disorders. It would help employees solve their personal problems. In general, the EAP project includes four aspects: enterprise survey, research and recommendations, publicity and promotion, education and training, and psychological consultation and treatment. [5]

China's EAP concept and related activities were first introduced by cross-border companies and psychologists from the West. In 1997, South Korea's Samsung Group invited Professor Zhang Xichao of the School of Psychology of Beijing Normal University for psychological training for the first time. In March 2001, the employee assistance program implemented by Lenovo's Customer Service Department also marked the birth of the first complete EAP project in China. The project was of great significance in the development of EAP in China. And it became a template for the implementation of EAP in China. It also set a precedent for the localization of EAP projects. [6]

\section{THE ROLE OF MEDIA Literacy EDUCATION IN EMPLOYEE ASSISTANCE PROGRAM}

With the deepening of supply-side structural reforms, people are experiencing more physical and psychological pressure. These factors have made organizations, managers, and employees experience unprecedented challenges. How 
employees relieve work pressure and improve performance; how managers provide assistance services; and how organizations face transformation and development are all tough and urgent issues.

\section{A. The Role of Media Literacy Education in EAP Services in Organizations}

The quality of the organizational environment directly affects the true expression of employees. A good atmosphere can effectively increase the efficiency of the organization's service delivery. Different industries, companies of different sizes, and companies in different stages of development have different requirements. This requires the organization to be able to make better use of media information, to obtain effective factors in the vast amount of information, and to provide evidence for the development plan of the organization.

\section{B. The Role of Media Literacy Education in EAP Service for Managers}

Managers are the core of the company's development. They need to grasp different information, make decisions and strategic plans through judgments and screenings. This requires managers to have good media literacy. And then, each decision does not have serious consequences. The EPA project service is an effective management tool for managers. Managers can consult their own problems. And the judgment of media information can also save managers a lot of trouble. Then, it would improve team harmony.

\section{The Role of Media Literacy Education in EAP Services for Employees}

Employees are the main body of business development. They often bear more physical and psychological pressure. According to surveys, employees have experienced psychological depression and sub-health at different levels, which cannot be overlooked in EAP project services. While employees are under physical and psychological pressure, they will also find ways to relieve themselves. For example, they would ease themselves through the network. And the complexity of media information will cause problems to employees. They are unable to distinguish the true and false information. And even, it would cause the tragedy. This requires the employees to carry out scientific media literacy education and improve their media literacy. It may achieve the effect that the employees can manage themselves and educate themselves.

\section{INTEGRATION OF MEDIA LITERACY EDUCATION AND EMPLOYEE ASSISTANCE PROGRAM}

\section{A. The Development of Employee Assistance Program Determines the Inevitability and Feasibility of Media Literacy Education}

The main contents of employee assistance program include issues such as physical and mental health, career problems, legal disputes, and financial issues, which are needed to be solved for the employees. With the rapid development of the information age, the previous methods of helping and supporting are also changing. A single use of traditional methods can no longer meet the needs of employees. At the same time, the frequency of use of media information by employees and the content involved are also expanding. Many employees have moved from being passive recipients of help to being initiative to seek help. The media literacy education lies in that when employees actively seek help information, they can better screen and judge the media information, and can use the media information correctly. The media information obtained can provide effective help for their own problems. [7]

Employee assistance programs require the introduction of media literacy education. Looking at the development of the economic era, all factors in the economic world are changing with the development of the times. Living in the information age, companies should make full use of media information when conducting employee assistance programs. When using media information, they must maintain reflection and criticism. For the crisis public relations, or when employees encounter difficulties, the correct guidance of public opinion and the correct information guidance, media literacy is the ability to provide analysis and judgment on media information, enabling companies to "help them to fish" while helping employees. The implementation of employee assistance program requires the intervention of various media information. And it would provide evidence for the supporting content. Media literacy education meets the requirements of employee assistance program, leaving employees free from negative information.

\section{B. Conditions for the Integration of Media Literacy Education and Employee Assistance Program}

Employees of the company are the main body of the EAP project. The improvement of media literacy of the employees will also have an effect on daily life and work. At the same time, it will also affect the formulation and implementation of employee assistance program.

It would improve cognition of media literacy education. The multi-cultural and massive information has brought a lot of impact on employees. The employee assistance program should help employees improve their ability in information processing while helping employees solve problems.

It should integrate media literacy education into employee assistance programs. In order to better integrate the actual situation of the employees with EAP projects, it would improve the employees. In the process of carrying out employee assistance program, the implementation content of media literacy education should be added. In the entire employee assistance program, the media literacy education module was added. A corresponding evaluation system was formulated to promote the integration of media literacy education and employee assistance program.

It should establish research institutions related to employee assistance program and media literacy education. Research institutions should be made up of the instructors of employee assistance program and media literacy education experts. They should set up regular or irregular training 
courses and forums to conduct practical research on the integration of media literacy education and employee assistance program. And it should combine theory with practice. Then, it should publish related reading. The establishment of an institution can effectively promote the sharing of media literacy education resources and experience in the employee assistance program. And it can establish bridges with governments and enterprises to provide a communication platform. [8]

\section{CONCLUSION}

In the information age, media culture has become the main spiritual content in people's lives. And it affects people's words and deeds and lifestyle all the time. Under such a cultural background, the employee assistance program has been given new meaning under the new requirements of the new era. As an important part of the operating organization, the organization members should shoulder the responsibilities of the times and history. While helping the employees, they should enhance their ability to independently criticize the media information and effectively integrate employee assistance program with media literacy education.

\section{REFERENCES}

[1] Wang Haoyu. The Integration of Ideological and Moral Education and Media Literacy Education [J], Political Education in Middle School, 2014(11): 76-79.

[2] Bu Wei. On the Meaning, Content and Method of Media Education [J], Modern Communication, 1997(1): 32.

[3] Sun Weiguo, Zhu Zhiting. Media Literacy Education: New Concept of Modern Education — An Overview of Media Literacy Education at Home and Abroad [J], E-education Research, 2006, (2): 18-23.

[4] Wang Haoyu. Research on the Questionnaire Making of Media Literacy Survey for Middle School Students [J], Education Observations, October 2017, 20th Issue, Second Half: 7-8.

[5] Zhang Xichao. Effective Ways to Improve Corporate Performance with Employee Effectiveness Program (EAP) [J], Economy, 2003, 3: 57-59.

[6] Wang Haoyu, Pan Jingshuang. On the Issues and Countermeasures of EAP Implementation in Small-scale Enterprises in China [J], Modern Business, No. 243, May 2011, No. 14: 202-203.

[7] Han Zifeng, Wang Haoyu. Integration of Media Literacy Education and Employee Assistance Program (EAP) [J], Commercial Economy, 2017, Issue 9: 90-91.

[8] Pan Jingshuang, Li Haoyu, Wang Haoyu. Application Conditions and Functions of EAP in Small Enterprises in China [J], Times Economics and Trade, September 2011, No. 218, p. 10. 